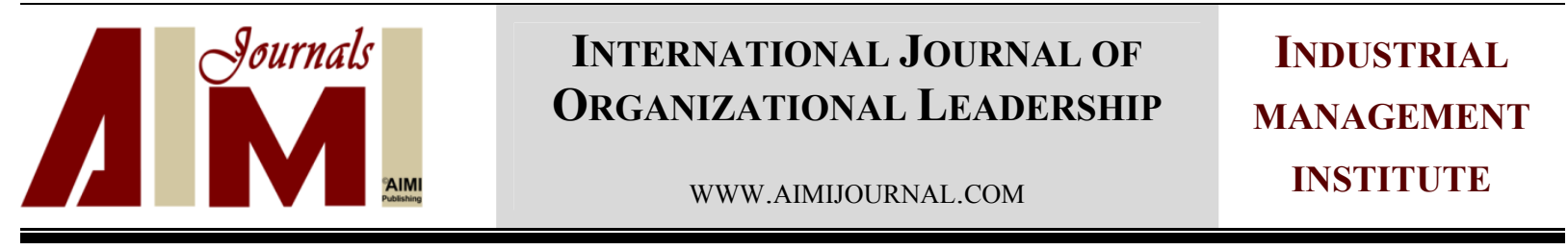

\title{
Relationship between Goal Orientation and Employee Creativity: A Mediating Role of Creative Self-Efficacy
}

\author{
Sajid Rahman Khattak ${ }^{1^{*}}$, Zafar Saleem ${ }^{2}$, Hadayat Khan ${ }^{3}$ \\ ${ }^{1}$ Assistant Professor Qurtuba University Peshawar \\ ${ }^{2} \mathrm{PhD}$ Scholar NUML Islamabad \\ ${ }^{3} \mathrm{PhD}$ Scholar KKKUK
}

\begin{abstract}
Keywords:

Learning Goal Orientation, Performance Goal

Orientation, Creative Self-

efficacy, Employee

Creativity

Received

18 November 2016

Received in revised form 10 November 2017

Accepted

24 November 2017

Correspondence:

Sajidktk99@yahoo.com

This paper aims to investigate the effect of learning and performance goal orientations on employee creativity through a mediating role of creative self-efficacy. The population of the study consists of all level of managers of commercial banking sector of Pakistan. Through stratified sampling technique a total 400 managers were selected for the study. Data was collected through a structured questionnaire having a five point Likert scale. The study found that both learning and performance goal orientations have positive and significant association with employee creativity. The study also found that creative self-efficacy partially mediates the relationship between goal orientations and employee creativity. The study highlights implications and future research directions.

(C)AIMI Journals

According to psychologists, achievement situations shape the behaviors and interpretation of events when individuals perceived their goals. This is particularly important in situations how individuals respond when they fail in goal achievement or when facing difficult task. According to goal orientation theory, an individual pursues two types of goals, namely learning goal orientation and performance goal orientation. Learning goal orientation pushes for mastery responses from individuals, which seeks to improve their skills by pursuing challenging tasks, whereas a performance orientation drives individuals to avoid difficult and challenging tasks. Thus, employees' goal orientations provide base for employees' creative efforts. Goal orientation
\end{abstract}


theory is generally considered to explain attitudes and behaviors of the employees in work place (Zhang \& Bartol, 2010).

Performance goal oriented individuals are interested in showing their skills and competencies to others and always seek positive feedback from others. Such individuals take little interest in difficult task and take such task in hand where success is sure. They favor status quo, because they lack confidence in performing new task because their reputation and performance will be negatively affected. On the other hand, employees with a learning orientation are confident in their abilities and believe that experience and continuous effort further improve their abilities. Such individuals enjoy challenging and difficult tasks, they are interested in such situations that increase their knowledge and promote their personal growth. Moreover, such individuals apply new learning approaches and they do not accept failure (Baker \& Sinkula, 2002). It is evident from the above discussion that learning orientation improves the ability of individuals while performance oriented individuals are interested in describing their ability. These two orientations are not mutually exclusive. An individual may possess both factors of goal orientation simultaneously.

Learning oriented employees enjoy to discover new processes and techniques in order to perform their jobs effectively (Runco \& Acar, 2012). They also learn from continuous learning and mistakes and improve past performance (Zhang \& Bartol, 2010). Learning orientation nourished task domain skills of employees by enabling them to combine the existing and new ideas to respond to the different situations. Employees with learning orientation see themselves as curious, and also different tasks attract them. When approaching a problem, such individuals are risk taker and have no fear regarding failure (Harris \& Flaming, 2005). Consequently, the working styles of such individuals are cognitive and conductive which ultimately lead to enhance creativity (Amabile, 1988). Furthermore, learning orientation is also considered as an important motivational impetus. Tasks complexity will bring motivations and they like to perform difficult tasks. Due to their self-improvement and self-belief, they seek new challenges (Zhang \& Bartol, 2010). They considered failure in the current tasks as an opportunity to learn and to perform the best in the future (Baker \& Sinkula, 2002). Therefore, these individual foster creativities through enhancement of job related skills and having a great potential to solve a problem (Wang, Tsai, \& Tsai, 2014).

On the other hand, performance oriented individuals ignore such types of tasks where they feel failure and try to maintain their abilities in the specific tasks which they perform well. Concerning creativity relevant skills, such individuals have not taken risks regarding new innovations, because their outcomes are unclear and they consider failure as an inferiority (Gong, Kim, Lee, \& Zhu, 2013). Such individuals withdraw their effort where they feel failure or in case where their performance is not good, because they view that their results measures their capabilities.

Researchers link learning orientation with employee creativity and found that both are positively associated (Gong, Huang, \& Farh, 2009; Ghafoor, Qureshi, Azeemi, \& Hijazi, 2011; Yildiz \& Özcan, 2014). However, literature regarding the relationship of performance orientation and employee creativity is limited. Thus, the aim of the current paper is to link both performance orientation and learning orientation with employee creativity to know whether performance orientation enhance employee creativity. Also, few studies highlighted the mediating role of 
creative self-efficacy on the relationship of goal orientation and employee creativity and found mix results. Thus, this study also tries to verify the mediating role of creative self-efficacy on the relationship of goal orientations and employee creativity.

\section{Research Hypotheses}

$\mathbf{H}_{1}$ : Learning orientation is significantly related to employees' creativity.

$\mathbf{H}_{2}$ : Performance orientation is significantly related to employees' creativity

$\mathbf{H}_{3}$ : Creative self-efficacy mediates the significant relationship between learning orientation and employees' creativity.

$\mathbf{H}_{4}$ : Creative self-efficacy mediates the significant relationship between performance orientation and employees' creativity.

\section{Method}

Population of the study consists of all level of managers including branch managers, operational managers, business development managers, HR managers, marketing managers, and account and finance managers of banking sector of Pakistan. Stratified sampling technique was used and through this technique, the study finally selected 400 managers of all level from the selected banks located in Rawalpindi, Islamabad, and Peshawar. Data was collected through a structured close ended questionnaire. Reliability and validity of the questionnaire was checked and which were found to be satisfactory.

\section{Results}

Table 1 presents the values of Cronbach's alpha of the study variables.

Table 1

Cronbach's Alpha of Variables

\begin{tabular}{lcc}
\hline Variables & Cronbach's Alpha & Number of Items \\
\hline Employee Creativity & 0.88 & 6 \\
Creative Self-efficacy & 0.88 & 6 \\
Goal Orientations & 0.82 & 14 \\
Overall Model & 0.93 & 26 \\
\hline
\end{tabular}

According to Table 1, the value of Cronbach's alpha is greater than 0.6 for all items, so all items used in the study are highly reliable. Thus, the values of Cronbach's alpha of all the items of the current study are in acceptable range and place in the excellent categories. Therefore, the instrument used to collect data have a good internal consistency.

Table 2 exhibits the correlation matrix of the study variables.

Table 2

Correlation Coefficients of Variables

\begin{tabular}{llll}
\hline & EC & GOP & GOL \\
\hline EC & 1 & & \\
GOP & $0.620^{* *}$ & 1 & 1 \\
GOL & $0.772^{* *}$ & $0.401^{* *}$ & 1 \\
\hline
\end{tabular}


Table 2 shows that the independent variables are highly and positively correlated with the dependent variable. According to the Table 2, all values of correlation coefficient are below 0.8 which indicate that there is no issue of multicollinearity among independent variables.

Table 3 clearly indicates the regression coefficients.

Table 3

\begin{tabular}{cccccc} 
Regression Coefficients \\
\hline \multirow{2}{*}{ Models } & Unstandardized Coefficients & \multicolumn{5}{l}{ Standardized Coefficients } \\
\cline { 2 - 6 } & $\mathrm{B}$ & Std. Error & $\beta$ & $\mathrm{t}$ & Sig. \\
\hline 1(Constant) & -24.15 & 2.59 & & -9.30 & 0.00 \\
GOP & 0.499 & 0.06 & 0.33 & 7.53 & 0.00 \\
GOL & 0.826 & 0.07 & 0.07 & 10.42 & 0.00 \\
R=0.87 & & & & & \\
R2 $=0.76$ & & & & & \\
F=276.66 & & & & \\
\hline
\end{tabular}

The summary of independent variables, namely performance goal orientation (GOP) and learning goal Orientation (GOL) are reported in Table 3. The value of $\mathrm{R}^{2}$ is 0.76 , which indicates that both predictor variables explain 76.2 percent of the variance in our dependent variable EC. The last column of the table report Durbin-Watson value. Here the value of Durbin-Watson is 1.818, which lies in the acceptable range of 1.5 to 2.5. Hence, it is also confirmed that there is no issue of autocorrelation in the data. The above table also shows ANOVA statistics of our predictor variables and predicted variable EC. ANOVA statistic tells about model fitness. The most important value in the above table is $\mathrm{F}$-statistic value. The value of F-statistic is 276.66 . Thus, the overall regression model of our study is fit. The Fstatistic value is the result of residual mean square and regression mean square value. In this case, the residual mean square value is 6.48 and regression mean square value is 1794.66 , which significantly contribute to the F-statistic value and as a result, the overall model is fit as shown in Table 3. The Table also represents the regression coefficients of our independent variables, namely GOP and GOL with dependent variable EC. The coefficient of GOP is positive 0.49 , and $t-$ value is 7.52 , which is statistically significant at $95 \%$ confidence interval. Similarly, the coefficient of GOL is positive 0.82 , and its $t-$ value is 10.42 , which is statistically significant at $95 \%$ confidence interval or at 0.05 level of confidence.

\section{Relationship between GOP and EC with Mediator CSE}

Step 1: Relationship between Independent Variable and Mediating Variable

Table 4 represents the model summary and coefficients.

$\begin{array}{lllllllllll}\text { Model } & \text { coeff } & \text { se } & \text { F } & \text { df1 } & \text { df2 } & t & p & \text { LLCI } & \text { ULCI }\end{array}$




\begin{tabular}{cccccccccc}
\hline Constant & 7.54 & 1.34 & 163.32 & 1 & 348 & 5.60 & 0.00 & 4.90 & 10.197 \\
$\mathrm{GOP}$ & 0.72 & 0.05 & & & & & 0.00 & 0.61 & 0.83 \\
$\mathrm{R}=0.56$ & & & & & & & & & \\
& & & & & & & & & \\
$\mathrm{R}^{2}=0.31$ & & & & & & & & & \\
$\mathrm{P}=0.00$ &
\end{tabular}

Table 4 reports model summary of the relationship between predictor variable GOP and dependent variable CSE. As it is shown, $\mathrm{R}^{2}$ value is 0.31 , which shows that predictor variable GOP explains $31.94 \%$ of the variance in the predicted variable CSE. The table also shows the regression coefficients of predictor and predicted variable. It is evident from the table that GOP is significantly associated with $\operatorname{CSE}(\mathrm{B}=0.72, \mathrm{p}<0.05)$. So, the first requirement for mediation analysis is fulfilled as suggested by Baron and Kenny (1986).

\section{Step 2: Relationship between Independent Variable and Dependent Variable}

Table 5 shows the model summary and coefficients.

Table 5

Model Summary \& Coefficients

\begin{tabular}{cccccccccc}
\hline Model & coeff & se & F & df1 & df2 & t & p & LLCI & ULCI \\
\hline Constant & -7.64 & 2.05 & 217.35 & 1 & 348 & -3.71 & 0.00 & -11.68 & -3.59 \\
GOP & 1.27 & 0.86 & & & & & 0.00 & 1.10 & 1.44 \\
$\mathrm{R}=0.62$ & & & & & & & & & \\
$\mathrm{R}^{2}=0.38$ & & & & & & & & & \\
$\mathrm{P}=0.00$ & & & & & & & & & \\
\hline
\end{tabular}

Outcome: EC

Table 5 represents the values of $R, R^{2}, F$, and $P$. The value of $R^{2}$ is 0.38 , which shows that predictor variable GOP explains $38.45 \%$ of the variance in dependent variable EC. The F-statistic value tells about model fitness. Here, the $F$ value is 217.35 . This high value of $F$ indicates that our model is fit which is also confirmed by $\mathrm{p}$-value. Following this, the table also shows the regression coefficients of predictor and predicted variable. It is evident from the table that GOP has significant relationship with EC $(\mathrm{B}=1.27, \mathrm{p}<0.05)$. So, the second requirement for mediation analysis is fulfilled as suggested by Baron and Kenny (1986).

Step 3 and 4: Relationship of Independent and Mediating Variables with Dependent Variable

Table 6 exhibits the model summary and coefficients.

$\begin{array}{lllllllllll}\text { Model } & \text { coeff } & \text { se } & \text { F } & \text { df1 } & \text { df2 } & \text { t } & p & \text { LLCI } & \text { ULCI }\end{array}$




\begin{tabular}{cccccccccc}
\hline Constant & -18.04 & 0.92 & 1341.4 & 2 & 347 & -19.45 & 0.00 & -19.86 & -16.22 \\
CSE & 1.37 & 0.03 & & & & 38.96 & 0.00 & 1.30 & 1.447 \\
GOP & 0.27 & 0.04 & & & & 6.136 & 0.00 & 0.18 & 0.36 \\
$\mathrm{R}=0.94$ & & & & & & & & & \\
& & & & & & & & \\
$\mathrm{R}^{2}=0.88$ & & & & & & & & \\
$\mathrm{P}=0.00$ & & & & & & & & \\
Outcome: $\mathrm{EC}$
\end{tabular}

Table 6 reports model summary of the predictor variables and predicted variable. As shown in the table, the value of $\mathrm{R}^{2}$ is 0.88 , which shows that the predictors GOP and CSE explain 88.5 percent of the variance in the predicted variable EC. The above table also shows regression coefficients of independent variables and dependent variable. Moreover, the relationship between GOP and EC is significant at 95 percent confidence interval with the presence of mediator CSE. So, it is found that CSE partially mediates the relationship between GOP and EC. The total effect of GOP and CSE on EC is 1.27. The direct effect of GOP on EC is 0.27 and the indirect effect of GOP on EC through CSE is 0.99. On the basis of the above results, $\mathrm{H}_{3}$ is accepted. We also confirmed the mediating effect of CSE by conducting Sobel test. Table 7 represents the result of Sobel test. In this case the effect size is 0.99 , which is statistically greater than zero with 0.05 level of confidence. Also the significant $p$-value $(p<0.05)$ indicates that the mediating effect is found between these variables. Here, the p-value is significant; thus, CSE mediates the relationship between GOP and EC. However, the effect of CSE does not change the relationship between GOP and EC, therefore, CSE partially mediate the relationship between GOP and EC.

Table presents the Sobel test or normality theory test.

Table 7

Sobel Test or Normality Theory Test

\begin{tabular}{lccc}
\hline Effect & se & z & P \\
\hline 0.99 & 0.08 & 12.13 & 0.00 \\
\hline
\end{tabular}

Relationship between GOL and EC with Mediator CSE

Step 1: Relationship between Independent Variable and Mediating Variable

Table 8

Model Summary \& Coefficients

\begin{tabular}{cccccccccc}
\hline Model & coeff & se & $\mathrm{F}$ & $\mathrm{df1}$ & $\mathrm{df2}$ & $\mathrm{t}$ & $\mathrm{p}$ & LLCI & ULCI \\
\hline Constant & -8.55 & 1.42 & 545.068 & 1 & 348 & -5.99 & 0.00 & -11.35 & -5.74 \\
$\mathrm{GOP}$ & 0.96 & 0.04 & & & & 23.34 & 0.00 & 0.88 & 1.04 \\
$\mathrm{R}=0.78$ & & & & & & & & & \\
& & & & & & & & & \\
$\mathrm{R}^{2}=0.61$ & & & & & & & & & \\
$\mathrm{P}=0.00$ & & & & & & & & & \\
Outcome: CSE
\end{tabular}

The above table reports model summary of the relationship between predictor variable GOL and predicted variable CSE. As presented in the table, the value of $\mathrm{R}^{2}$ is 0.61 , which shows that 
predictor variable GOL explain $61.03 \%$ of the variance in the predicted variable CSE. The Fstatistic value is 545.06, which tells about the model fitness. Also $\mathrm{p}-$ value is significant ( $\mathrm{p}<$ 0.05), which means that our model is fit. The table represents regression coefficients of predictor and predicted variables. It is evident from the table that GOL is positively and significantly related with CSE $(p<0.05)$. So, the first requirement for mediation analysis is fulfilled as suggested by Baron and Kenny (1986).

\section{Step 2: Relationship between Independent Variable and Dependent Variable}

Table 9 indicates the model summary and coefficients.

Table 9

Model Summary \& Coefficients

\begin{tabular}{|c|c|c|c|c|c|c|c|c|c|}
\hline Model & coeff & se & $\mathrm{F}$ & df1 & df2 & $\mathrm{t}$ & $\mathrm{p}$ & LLCI & ULCI \\
\hline Constant & -30.19 & & 512.82 & 1 & 348 & -12.93 & 0.00 & -34.78 & -25.60 \\
\hline GOP & 1.53 & 2.33 & & & & 22.64 & 0.00 & 1.40 & 1.66 \\
\hline $\mathrm{R}=0.77$ & & 0.06 & & & & & & & \\
\hline \multicolumn{10}{|l|}{$\mathrm{R}^{2}=0.59$} \\
\hline $\mathrm{P}=0.00$ & & & & & & & & & \\
\hline
\end{tabular}

Table 9 shows the values of $R, R^{2}, F$, and $P$. The value of $R^{2}$ is 0.59 , which shows that predictor variable GOL explains $59.57 \%$ of the variance in dependent variable EC. The Fstatistic value tells about model fitness. Here, the $\mathrm{F}$ value is 512.82 . The table also shows regression coefficients of the predictor and predicted variables. It is evident from the table, that GOL is positive and it has significant relationship with EC $(p>0.05)$. The regression coefficient indicates that a unit change in predictor variable (GOL) will bring a positive change of 1.53 in the dependent variable (EC). So, the second requirement for mediation analysis is fulfilled as suggested by Baron and Kenny (1986).

Step 3 and 4: Relationship of Independent and Mediating Variables with Dependent Variable

Table 10 clearly indicates the model summary and coefficient.

Table 10

Model Summary \& Coefficients

\begin{tabular}{cccccccccc}
\hline Model & coeff & se & F & df1 & df2 & t & p & LLCI & ULCI \\
\hline Constant & -18.51 & 1.35 & 1243.35 & 2 & & -5.99 & 0.00 & -21.16 & -15.85 \\
CSE & 1.36 & 0.04 & & & 347 & 28.55 & 0.00 & 1.27 & 1.46 \\
GOL & 0.21 & 0.05 & & & & 3.57 & 0.00 & 0.09 & 0.33 \\
& & & & & & & & & \\
$\mathrm{R}=0.93$ & & & & & & & & & \\
$\mathrm{R}^{2}=0.87$ & & & & & & & & & \\
$\mathrm{P}=0.00$ & & & & & & & & & \\
Outcome: $\mathrm{EC}$
\end{tabular}

Table 10 reports model summary of the predictor variables and predicted variable. The value of $\mathrm{R}^{2}$ is 0.87 , which shows that the predictors GOL and CSE explains 87.75 percent of the 
variance in the predicted variable EC. Table 10 also shows the regression coefficients of independent variables and dependent variable. As it is shown, the relationship between GOL and EC is significant at 95 percent confidence interval with the presence of mediator CSE. So, it is found that CSE partially mediates the relationship between GOL and EC. The total effect of predictor variables and predicted variable is 1.53 . The direct effect of predictor variable (GOL) on predicted variable (EC) is 0.21 . The indirect effect of GOL on EC through mediating variable CSE is 1.32. We also confirmed the mediating effect of CSE by conducting Sobel test. Table 11 represents the results of Sobel test. In this case the effect size is 1.32, which is statistically greater than zero with 0.05 level of confidence. Also, the significant $p$-value $(p<0.05)$ indicates that CSE mediate the relationship between these variables. Here, the $p$ value is significant; thus, it can be concluded CSE mediate the relationship between GOL and EC. However, the effect of CSE on the relationship between GOL and EC does not change the relationship between these variables. Therefore, CSE partially mediate the relationship between GOL and EC.

Table 11 shows the Sobel test or normality theory test.

Table 11

Sobel Test or Normality Theory Test

\begin{tabular}{cccc}
\hline Effect & se & z & P \\
\hline 1.32 & 0.07 & 17.99 & 0.00 \\
\hline
\end{tabular}

\section{Discussion and Conclusion}

Several plausible reasons support the idea that goal orientation is beneficial for CSE maintenance and formation. First, goal orientation is grounded in the conception of ability which means that ability is flexible (Dweck, 1986; Dweck \& Leggett, 1988). These conceptions build efficacy beliefs (Bandura, 1998). Second, goal orientation mainly focuses on competence development (Dweck, 1986). Such learning and performance oriented individuals accumulate experience over time of successful mastery. Having such combination of skills and experiences, these followers will produce more creative and innovative ideas due to high self-efficacy. Third, due to the association of provenance pattern with goal orientations in the front of impediments, it helps an individual to maintain CSE. Learning oriented individuals do not delay creative actions but they attribute them to such factors like ineffective strategies or insufficient effort from an individual. As a result, such individuals are faced little involvement of aversive encouragement and thus, they try to maintain their self-efficacy in creative actions. Finally, goal oriented employees mainly focus on the development of self-competence. However, creative actions are risky and challenging (Bandura, 1998). In the process of creative endeavors, negative reactions may also arise from other employees but goal oriented individuals mainly focus on their self-improvement. In other words, goal oriented individuals mainly focus on how to improve their competence throughout the ambiguity of the creative journey.

The results of the current study suggest that CSE partially mediates the relationship between GOL, GOP and EC. One possible explanation for such result as that CSE is the belief on their ability and skills to produce something new; if a person does not belief in his ability then, how he or she can produce new ideas. The results of the current study are in line with Gong et al. (2009); however, they found that CSE fully mediates the relationship between GOL and EC. The 
result is also consistent with Ghafoor et al. (2011). They also found that CSE mediates the relationship of GOL with EC.

The purpose of this study is to identify the relationship of goal orientations (learning goal orientation and performance goal orientation) with employee creativity in the presence of mediator creative self-efficacy in the banking organization of Pakistan. Based on the results of regression analyses, it is concluded that performance goal orientation and learning goal orientation have positive and significant relationship with employee creativity. Thus, all these variables are statistically significant predictors of employee creativity in banking sector of Pakistan. Managers of the commercial banks exhibit learning goal orientation in order to enhance creativity in the organization. Similarly, managers of commercial banks exhibit performance goal orientation to improve employee creativity in their respective organizations. The results of the current study are in line with historical research findings in the field of strategic human resource management. The results of the simple regression model and multiple regression model show that learning goal orientation is the most influencing independent variable followed by performance goal orientation. In short, we conclude that performance and learning goal orientations are likely to enhance individual creativity over time.

Although, this study contributes a new insight to the existing literature but this study has some limitations as well. First, the current study investigates the relationship of both learning and performance goal orientations with employee creativity but it did not test the effect of each dimension of learning orientation, namely intra organizational knowledge sharing, open mindedness, shared vision, and commitment to learning. In future, researchers may try to explore the effect of intra organizational knowledge sharing, open mindedness, shared vision, and commitment to learning on employee creativity. Second, this study was conducted in banking sector of Pakistan: In future, researchers may select other business organizations especially telecom sector and software houses because these organizations solely compete on product innovation and creativity. Third, we tested the hypotheses using managerial level employees in banking sector; to this end, future research should replicate our finding by selecting middle and lower level employees. Finally, our study was conducted in Pakistan. Future studies should be conducted in other areas or countries to examine the differences that may exist.

\section{References}

Amabile, T. M. (1988). A model of creativity and innovation in organizations. In B. M. Staw, \& L. L. Cummings (Eds.), Research in organizational behavior (pp. 123-167). Greenwich, CT: JAI Press.

Baker, W. E., \& Sinkula, J. M. (2002). Market orientation, learning orientation and product innovation: Delving into the organization's black box. Journal of Market-Focused Management, 5(1), 5-23.

Bandura, A. (1998). Health promotion from the perspective of social cognitive theory. Psychology \& Health, 13(4), 623-649.

Baron, R. M., \& Kenny, D. A. (1986). The moderator-mediator variable distinction in social psychological research: Conceptual, strategic, and statistical considerations. Journal of Personality \& Social Psychology, 51, 1173-1182.

Dweck, C. S. (1986). Motivational processes affecting learning. American Psychologist, 41(10), 1040-1048.

Dweck, C. S., \& Leggett, E. L. (1988). A social-cognitive approach to motivation and personality. Psychological Review, 95(2), 256-273.

Ghafoor, A., Qureshi, T. M., Azeemi, H. R., \& Hijazi, S. T. (2011). Mediating role of creative self-efficacy. African Journal of Business Management, 5(27), 11093-11103. 
Gong, Y., Huang, J. C., \& Farh, J. L. (2009). Employee learning orientation, transformational leadership, and employee creativity: The mediating role of employee creative self-efficacy. Academy of Management Journal, 52(4), 765-778.

Gong, Y., Kim, T. Y., Lee, D. R., \& Zhu, J. (2013). A multilevel model of team goal orientation, information exchange, and creativity. Academy of Management Journal, 56(3), 827-851.

Harris, E. G., \& Fleming, D. E. (2005). Assessing the human element in service personality formation: personality congruency and the Five Factor Model. Journal of Services Marketing, 19(4), 187-198.

Runco, M. A., \& Acar, S. (2012). Divergent thinking as an indicator of creative potential. Creativity Research Journal, 24, 6675 .

Wang, C. J., Tsai, H. T., \& Tsai, M. T. (2014). Linking transformational leadership and employee creativity in the hospitality industry: The influences of creative role identity, creative self-efficacy, and job complexity. Tourism Management, 40, 79 89.

Yıldı, M. L., \& Özcan, E. D. (2014). Organizational climate as a moderator of the relationship between transformational leadership and creativity. International Journal of Business \& Management, 2(1), 76-87.

Zhang, X., \& Bartol, K. M. (2010). Linking empowering leadership and employee creativity: The influence of psychological empowerment, intrinsic motivation, and creative process engagement. Academy of Management Journal, 53(1), 107-128. 